\title{
Community-based canvassing to improve the U.S. Census Bureau's Master Address File: California's experience in LUCA 2018
}

\author{
Ed Kissam ${ }^{\mathrm{a}, *}$, Cindy Quezada ${ }^{\mathrm{b}}$ and Jo Ann Intili ${ }^{\mathrm{a}}$ \\ ${ }^{a}$ Werner-Kohnstamm Family Giving Fund, Oakland, CA, USA \\ ${ }^{\mathrm{b}}$ Central Valley Immigrant Integration Collaborative, Fresno, CA, USA
}

\begin{abstract}
This article documents a novel approach used to improve the census address list in California as part of the LUCA (Local Update of Census Addresses) phase of the decennial census. Local government and community-based organizations partnered to conduct in-field address canvassing to identify hidden housing previously omitted from the list and not included in local administrative records used for in-office address LUCA review of address lists. Areas with about 1 million housing units were canvassed and 13,000 newly-identified housing units were added to the address list. The tract-level "yield" of newlyidentified hidden housing units varied but overall return on investment was high.

Adding $1.3 \%$ newly-identified housing units to the pre-LUCA address list means that about 46,000 California low-income residents who otherwise would have only a slim chance of being enumerated can be counted in 2020 . This represent a significant contribution toward overcoming the longstanding undercount of minorities and immigrants in these neighborhoods.

This strategy, occasioned by the U.S. Census Bureau's decision to limit its own in-field address canvassing to only $30 \%$ of the nation, has particular relevance for census enumeration in less-developed countries. It demonstrates the efficacy of drawing on social, cultural, and civic capital in communities with limited financial resources to ameliorate the negative impact that budget constraints on central government funding have on fair and accurate census enumeration.
\end{abstract}

Keywords: LUCA, Master Address File, address canvassing, differential census undercount, complex households, hidden housing units

\section{Overview}

A major cause of differential census undercount in the United States is that "unconventional", often hidden, housing units where many low-income families, predominantly minorities and immigrants, live are left off the U.S. Census Bureau's address list. Families living in these sorts of housing situations - converted garages, basements, back of the house add-ons, informally-built living quarters, RV's (recreational vehicles), and trailers in backyards - will not receive an invitation to participate in Census 2020 or receive any follow-up if they fail to respond.

Community-based address canvassing is a new strategic approach designed to identify these uncon-

${ }^{*}$ Corresponding author: Ed Kissam, Werner-Kohnstamm Family Giving Fund, Oakland, CA, USA. E-mail: edkissam@me.com. ventional and/or hidden housing units and add them to the U.S. Census Bureau's address list. The strategy is to mobilize outreach staff and/or volunteers from local grassroots organizations and/or service programs already working in "hard to count" communities to identify the unconventional housing units in these neighborhoods and deploy these local canvassers to work in partnership with local government to propose these newly-identified housing units be added to the final address list, referred to as the Master Address File (MAF) that will be used in Census 2020.

This collaborative effort, referred to as LUCA (Local Update of Census Addresses) was instituted in 1998 and has been refined in past decades. The Census 2010 operation was carefully evaluated providing some useful insights for improvement [1]. LUCA is more important for Census 2020 than ever before, because, as a result of a decade of budget constraints, the 
U.S. Census Bureau decided to cut back its own infield address canvassing to include only $30 \%$ of U.S. addresses [2].

The community-based address canvassing approach discussed here was piloted in December, 2017-January, 2018 in three counties in California. Areas with about 41,000 households were canvassed. In the course of the pilot, 1,709 unconventional housing units were identified. This represented an addition of $4.1 \%$ housing units to the pre-LUCA address list [3]. Based on findings from this pilot, the community-based address canvassing approach was then adopted and adapted by three additional, predominantly urban, counties and in one additional predominantly rural county. In two counties, there were local agreements that large municipalities would take the lead in implementing the community-based address canvassing in their jurisdiction while county teams would lead the effort in other areas.

Ultimately, variations of the community-based address canvassing strategy were implemented as a component of overall LUCA review of the Census Bureau's Master Address File (MAF) in six counties. In the LUCA-linked rollout areas about 1,027,000 housing units (HU's) were canvassed and about 13,000 unconventional and/or hidden housing units not previously included in local address lists or the Census Bureau's pre-LUCA address file were identified. This represents a "yield" where newly-identified unconventional housing units increase the pre-LUCA MAF by about $1.3 \%$.

Identifying the additional unconventional housing units not previously included in the MAF will increase California's census count in 2020 by about 46,000 persons who, otherwise, would probably not have been enumerated. The exact number of persons added to the census count will depend on the number of people living in each newly-added housing unit.

Because the census tracts targeted for the community-based canvassing approach were "hard to count" ones with concentrations of low-income minority and immigrant populations, the resulting MAF file improvement will not only lead to a more complete census count but, at the same time, lead to a more accurate count, by directly ameliorating differential undercount of low-income minority and immigrant households in the communities where the strategy was implemented, making for a fairer count.

California's municipalities' and counties' experience with community-based address canvassing as part of LUCA is relevant to less-developed countries. It demonstrates a successful practical collaborative strat- egy for deploying social and civic capital from disadvantaged communities in response to central government's failure to allocate adequate financial resources to support a crucial phase of census operations.

\section{How community-based address canvassing to identify hidden housing units can improve the Census Bureau's Address List}

The decennial census is a survey - meant to include $100 \%$ of the U.S. population: "to count everyone once, only once, and in the right place". That is why developing a complete address list is so important for census accuracy and fairness. If the place a family lives is not included in the U.S. Census Bureau's address list - which is built primarily on multiple federal data sources and augmented with administrative data from local government - that household does not get an invitation to respond to the census and is very unlikely to be contacted in the NRFU (non-response followup) phase of decennial census data-collection [4].

The U.S. Census Bureau's address list is, inevitably, incomplete. Several decades of research in inner-city neighborhoods and farmworker communities show that one-third to one-half of total census undercount stems from "total household omission" because the place a family lives is not included in the MAF and does not receive an invitation to respond to the census. A Census Bureau study of undercount in Los Angeles basin communities reported by Fein and West, showed that $3.3 \%$ of housing units in the predominantly Latino study region were not on its address list [5,6]. Subsequent ethnographic and survey research in immigrant communities [7-9] showed and that even more of the unconventional housing is missed in California farmworker communities [9-11].

It is reasonable to ask how prevalent is this type of unconventional and hidden housing in 2018? There are reasons to believe it is at least as prevalent now as in the past - because housing costs have risen faster than lowwage earners' income. More than half $(55.5 \%)$ of California low-income households pay more than half of their income for shelter. [13] Consequently, the prevalence of low-income households living in "unconventional" housing has very likely increased greatly during the past decade in California and in some other areas of the U.S. and will increase further by 2020 . This means that increasing numbers of low-income minority and immigrant families are at risk of being left out of the decennial census because of their marginal housing accommodations. 
Increasingly sophisticated use of satellite imaging technology and increased attention by local governments to the utility of improving administrative records on housing stock in their jurisdiction also make important contributions to MAF completeness - but efficacy of such efforts varies. An additional problem is that that there is over-confidence in the capabilities of such technology. For example, satellite imagery, which does permit the identification of newly-constructed housing units, is not adequate to identify non-residential structures which have been converted into housing. Similarly, improvements in administrative record systems make them more useful but they continue to be incomplete - particularly in identifying actively-concealed unauthorized conversion of structures into occupied housing units.

As part of our exploration of the potential of community-based address canvassing, we examined the extent to which diligent in-field efforts might identify low-visibility housing units without postal addresses in a southern California farmworker community known to have a high proportion of unconventional housing where satellite imaging might be expected to be excellent (due to lack of cloud cover or forest cover). In the small area of the community where unconventional housing was concentrated, 5.8\% of the actual housing units were not included in the U.S Census Bureau's pre-LUCA address count file; when our analysis was extended to assess improvements to the MAF for the entire block group, which included a good deal of newly-built high-visibility affordable housing we did not canvass but where we assumed the MAF was accurate, the newly-identified unconventional housing units added $3.6 \%$ to the pre-LUCA MAF for the block group.

\section{MAF improvement outcomes from california's canvassing initiatives in LUCA 2018}

Partnerships between California LUCA participants and community-based organizations during LUCA were the basis for the local community-based address canvassing used to identify unconventional housing units to add to the MAF. The partnerships conducted canvassing in six counties, four of them predominantly urban, two of them predominantly rural. However, the vast majority of the canvassing took place in census tracts classified as urban ones.

In four of the counties, community-based organizations familiar with housing conditions in their local neighborhoods conducted address canvassing to identify unconventional housing units to submit to the Census Bureau's address list. However, in two counties, the in-field address canvassing teams included county employees as well as community-organization canvassers.

The approach used in implementing the strategy varied from community to community. In one urban county, for example, in addition to contracting with local community-based organizations, a knowledgeable local government worker was assigned to conduct canvassing. In another county, an experienced county planner supplemented identification of hidden housing units with observations based on satellite imagery in an area where housing was set back from the road on private property not easily accessible by in-field canvassers. Although implementation details varied, the efforts were successful in each of the areas. This sort of innovative adaptation to make effective use of local resources and adjust strategies to local community context has great promise.

In the four predominantly urban counties where county government led the LUCA community-based canvassing effort analyzed here, the in-field canvassing observations were integrated into overall LUCA review so that the resulting LUCA submissions from in-field canvassing were compared to the address lists provided to LUCA partners for review. Consequently, it is very likely that there were no duplications. In the two predominantly rural counties where canvassing took place, the community-based address canvassing initiative was implemented by a consortium of community-based organizations, the Central Valley Immigrant Integration Collaborative, and data were submitted directly to the California state LUCA liaison by Community Connect Labs, the organization which had developed the mobile application for secure transmission of data from canvassers to its hub and, then, on to the state.

Table 1 shows the results of the community-based canvassing efforts in the six counties - the number of newly-identified unconventional and/or hidden housing units and the percent "yield", that is, the number of newly-identified housing units as a percent of housing units included in the pre-LUCA MAF in the areas canvassed.

Where LUCA partners' records made it possible to tabulate the "yield" of newly-identified hidden housing units by census tract, we calculated yield for the overall area that was canvassed. In several of the counties, the LUCA-linked community-based canvassing efforts were targeted to neighborhood "hot spots" smaller than 
a census tract believed to have relatively more unconventional and/or hidden housing. In those cases, the specific sub-areas designated for canvassing were identified as block groups or GIS-based polygons and yield was reported for those particular areas. We used data from the U.S. Census Bureau June 2018 Planning Database (PDB) to estimate the overall number of housing units in each census tract where canvassing took place or used local government reports for estimating the pre-LUCA number of housing units where only part of a census tract was canvassed [14].

As can be seen in Table 1, the efficacy of the community based in-field canvassing varied substantially from one area to another, and even more from tract to tract. Multiple factors are likely to account for variations in canvassing efficacy: how narrowly or broadly each county targeted its canvassing efforts, the quality of the underlying MAF in the targeted areas, and local difficult-to-identify neighborhood variations in housing stock, and limitations of the targeting algorithm.

County A and County B where the communitybased canvassing effort was most widely implemented achieved lower average "yields" of added unconventional and/or hidden housing units because fewer of the targeted blocks generated a significant yield of newlyidentified housing units. For example, in County A, where the yield of newly-identified housing units was relatively low, one-third of the canvassed tracts generated a "yield" of only $0.33 \%$ newly-identified HU's or less. In County B, the yield was less than $0.33 \%$ in almost half the tracts canvassed. In City A, the yield was less than $0.33 \%$ in about one-third of the tracts canvassed.

In contrast, in County $\mathrm{C}$, canvassing generated a yield of $1 \%$ or more in all of the canvassed tracts but one. Similarly, in County E and in County F, where the community-based address canvassing was more narrowly targeted, the initiatives resulted in higher yields of newly-identified housing units on the average $7.1 \%$ and $2.6 \%$ respectively

The results of the community-based canvassing initiatives show that in-field canvassing can and should be targeted to maximize cost-effectiveness. Tract by tract review of the geographic distribution of the newlyidentified hidden housing units suggests that there are, generally, "hot spots" where concentrations of unconventional housing accommodation lead to problems in MAF quality. For example, in County A, even though the overall yield was lower than in other areas, community-based address canvassing added more than $5 \%$ to the inventory of housing units previously in the MAF for about $0.8 \%$ of the county's census tracts, while in County $\mathrm{C}$, the community-based address canvassing added more than $5 \%$ to the pre-LUCA MAF for $12 \%$ of the tracts.

Neighborhood housing patterns do not neatly conform to census geography so there is, inevitably, an imperfect correspondence between patterns of unconventional and/or hidden housing and census geography but targeting in-field canvassing efforts to focus on areas where the MAF is most likely to have missed unconventional and /or hidden housing units is feasible and affordable. The roll-out of community-based address canvassing initiatives as part of LUCA show that targeting similar areas in the course of the Census Bureau's own in-field address canvassing could cost-effectively make significant contributions to MAF quality.

\section{Socioeconomic and demographic characteristics of canvassed areas}

Improving the MAF by identifying and adding unconventional and/or hidden housing units where socially and/or economically marginal families live makes an important and direct contribution to ameliorating the longstanding problem of differential census undercount of racial/ethnic minorities. This is because the low-income, predominantly minority, households residing in housing units not included in the MAF are very unlikely to be enumerated otherwise. They will not receive invitations to respond online or a mailed census form, the housing unit they live in will not become part of the non-response follow up (NRFU) workload so they will not be interviewed by an enumerator and their lack of response will not be accounted for in tabulations of self-response rates. Although there are decennial census operations (Update/Enumerate and Update/Leave) which provide a way for households living in housing units not in the MAF to be enumerated, they will not be widely used given U.S. Census Bureau budget and staffing constraints.

The underlying principle for conducting the community-based in-field address canvassing as part of LUCA was that unconventional housing should be most prevalent in neighborhoods where economic pressures - on both property owners and local residents - led to the emergence of unconventional housing arrangements to make ends meet. Based on prior ethnographic research it was also hypothesized that un- 
Table 1

Results from community-based address canvassing to identify unconventional and/or hidden housing units

\begin{tabular}{|c|c|c|c|c|c|c|c|c|}
\hline County & City A & County A & County B & County $\mathrm{C}$ & County D & County E & County F & $\begin{array}{c}\text { All } \\
\text { canvassed areas }\end{array}$ \\
\hline HU's canvassed areas & 80,295 & 328,597 & 519,138 & 23,090 & 46,900 & 22,460 & 6,954 & $1,027,434$ \\
\hline \# HU's added & 1,744 & 4,568 & 3,100 & 1,964 & 571 & 592 & 491 & 13,030 \\
\hline $\begin{array}{l}\text { \% HU's added for overall } \\
\text { canvassed area }\end{array}$ & $2.2 \%$ & $1.65 \%$ & $0.6 \%$ & $8.5 \%$ & $1.2 \%$ & $2.6 \%$ & $7.1 \%$ & $1.3 \%$ \\
\hline Range in $\%$ yield of added & $0.03 \%$ to & $0.03 \%$ to & $0 \%$ to & $0 \%$ to & $0.04 \%$ to & $0.05 \%$ to & $0.2 \%$ to & $0 \%$ to \\
\hline HU's per tract & $28.3 \%$ & $15.75 \%$ & $21.5 \%$ & $53.5 \%$ & $6.1 \%$ & $5.4 \%$ & $8.1 \%$ & $53.5 \%$ \\
\hline $\begin{array}{l}\text { Persons/HU canvassed } \\
\text { areas }\end{array}$ & 3.7 & 3.8 & 3.1 & 3.4 & 3.2 & 3.5 & 3.6 & 3.5 \\
\hline \# of Tracts canvassed areas & 51 & 265 & 301 & 32 & 26 & 18 & 17 & 710 \\
\hline $\begin{array}{l}\text { Canvassed } \% \text { of tracts in } \\
\text { area }\end{array}$ & $100 \%$ & $11.3 \%$ & $100 \%$ & $20.1 \%$ & $12.3 \%$ & $3.8 \%$ & $8.5 \%$ & N/A \\
\hline
\end{tabular}

*In County A and County B, canvassing was sometimes targeted to a portion of a census tract predicted to be "high priority" for canvassing, e.g. excluding areas with industrial buildings, multi-unit "high rise" buildings where the MAF was believed to be accurate. Sub-areas of census tracts canvassed were, in most cases, block groups, but, in some cases block clusters or polygons within the tract. In County $\mathrm{F}$, canvassing was targeted to block groups. The estimate of housing units (HU's) in canvassed areas includes adjustments for these partially-canvassed tracts in those counties but not for tabulations for City A, County D, County E. The County A canvassing presented here does not include two large municipalities within this predominantly urban county. Persons/HU is based on the Census Bureau's PDB data for the tracts canvassed. The County B estimates do not include tracts within City A which was canvassed as a separate initiative. In tabulating reports we reviewed the city's and county's data to assure there was no duplication. The community-based address canvassing approach was also implemented in at least one additional large California city but we do not have tabulations for the outcomes from this initiative.

conventional housing arrangements were more likely to emerge in immigrant neighborhoods [15]. Consequently, in piloting the community-based address canvassing strategy, and in subsequent implementation, block groups or tracts to be canvassed were identified relying, in part, on a "bad MAF" targeting algorithm built from data drawn from the Census Bureau's Planning Database (PDB).

Table 2 shows that the community-based in-field address canvassing in six of the seven areas where the strategy was implemented did, indeed, cover areas with higher-than-average levels of socially-disadvantaged households compared to the state as a whole. In the remaining county (County B) which is, overall, a very affluent one with very high housing costs, there were, nonetheless, deep pockets of marginal housing occupied by socially marginalized families within the canvassed areas.

Table 2 shows that the neighborhoods where in-field community-based address canvassing added newlyidentified housing units are mostly ones with high proportions of households headed by non-citizens, racial/ethnic minority respondents, and heads of household with lower-than average educational attainment. Adding unconventional and/or hidden housing units to the MAF makes a direct contribution toward reducing the differential undercount of economicallydisadvantaged minority and immigrant populations in these areas.

The "bad MAF" areas targeted in the address canvassing where it was expected there would be higher- than-average prevalence of unconventional and/or hidden housing units are partially but not perfectly correlated with areas designated as "hard to count" based on predicted self-response rate (LRS). Our own analysis identified some areas with relatively low "hard to count" scores as likely to have MAF deficiencies and vice-versa, some with high scores did not appear to have much unconventional housing. This is inevitable - since there are multiple causes of census non-response. Being in a housing unit that is omitted from the MAF that, consequently, receives neither an invitation to respond online, a paper questionnaire, or a visit from an enumerator is only one, although it is an important one.

\section{Using and refining the algorithm used to guide targeted in-field address canvassing to identify Unconventional and/or Hidden Housing Units Not In The Census Sampling Frame}

The U.S. Census Bureau's Planning Database, made up of pooled data from ongoing periodic data collection in the American Community Survey (ACS) is a valuable resource for decennial census planning and operational implementation. However, it has limitations as a basis for targeted in-field address canvassing, because the low-visibility housing units left out of the MAF are also omitted from the ACS and, therefore, not directly identifiable in the planning database. 
Table 2

Demographic/socioeconomic profile of areas where unconventional and/or Hidden Housing Units Were Added to the MAF

\begin{tabular}{|c|c|c|c|c|c|c|c|c|}
\hline County & County A & County B & City A & County C & County D & County E & County F & State-wide \\
\hline $\begin{array}{l}\text { Av. LRS (low-response) score } \\
\text { For canvassed tracts }\end{array}$ & 30.5 & 21.6 & 25.0 & 26.1 & 27.4 & 28.4 & 31.7 & 25.0 \\
\hline Median\% pop. in poverty & $24.6 \%$ & $7.5 \%$ & $14.4 \%$ & $10.9 \%$ & $20.5 \%$ & $33.1 \%$ & $44.6 \%$ & $14.3 \%$ \\
\hline Median \% pop. in crowded housing & $22.7 \%$ & $6.2 \%$ & $17.3 \%$ & $16.5 \%$ & $10.7 \%$ & $12.2 \%$ & $17.8 \%$ & $8 \%$ \\
\hline $\begin{array}{l}\text { Median \% pop. Hispanic-headed } \\
\text { HH's }\end{array}$ & $84.6 \%$ & $22.3 \%$ & $48.4 \%$ & $45.9 \%$ & $54.8 \%$ & $72.7 \%$ & $68.7 \%$ & $39.1 \%$ \\
\hline $\begin{array}{l}\text { Median \% } \\
\text { Black-headed HH's }\end{array}$ & $1.5 \%$ & $2.0 \%$ & $2.5 \%$ & $2.0 \%$ & $10.9 \%$ & $3.6 \%$ & $6.1 \%$ & $6.5 \%$ \\
\hline $\begin{array}{l}\text { Median \%. } \\
\text { Asian-headed HH's }\end{array}$ & $1.6 \%$ & $27.3 \%$ & $22.7 \%$ & $14.3 \%$ & $10.0 \%$ & $5.9 \%$ & $7.2 \%$ & $15.2 \%$ \\
\hline Median \% minority-headed $\mathrm{HH}$ & $87.7 \%$ & $51.6 \%$ & $73.6 \%$ & $62.2 \%$ & $75.7 \%$ & $82.2 \%$ & $82.0 \%$ & $60.8 \%$ \\
\hline $\begin{array}{l}\text { Median } \% \text { of } \mathrm{HH} \text { heads } \mathrm{w} /<\mathrm{HS} \\
\text { education }\end{array}$ & $43.5 \%$ & $10.2 \%$ & $29.7 \%$ & $21.9 \%$ & $27.6 \%$ & $48.5 \%$ & $48.9 \%$ & $17.9 \%$ \\
\hline Median $\%$ of $\mathrm{HH}$ non-US citizens & $25.0 \%$ & $15.0 \%$ & $21.5 \%$ & $24.9 \%$ & $23.7 \%$ & $24.0 \%$ & $21.8 \%$ & $14.3 \%$ \\
\hline
\end{tabular}

${ }^{*}$ Household profile for the canvassed areas is based on 2018 PDB data for the canvassed tracts using ACS2012-2016 derived variables.

The ACS data tabulations are also very "noisy" at low levels of census geography - the block group and the census tract.

For these reasons, we advised local in-field address canvassing to rely heavily on local insights about housing patterns to guide targeted in-field address canvassing to identify low-visibility housing. Our advice to rely on local social, civic, and cultural capital, i.e. the insights from individuals living and working with "hard to count" populations and in diverse low-income neighborhoods in implementing local initiatives - is important, both in the United States and globally. Local community input from residents of "hard to count" areas and non-governmental grassroots organizations serving them, provided in a context where it is assured the information will not be used for building code or planning department enforcement, is a valuable resource for MAF improvement. This sort of knowledgeable local input, essentially augments central government's compromised capacity to fully understand the dynamics of low-income families' strategies for housing accommodations.

Debate about the need to rely on such "old fashioned" processes to improve the reliability of statistical research, given rapidly-developing technology for analyzing "big data" and powerful satellite imagery, reflects longstanding debate in the broader realm of "intelligence" - for economic or social planning or for political purposes. And the inevitable real-world conclusion need to be the same, that "human intelligence", i.e. reliance on resources of social and cultural capital, continues to be a crucial complement to analysis of datasets that, inevitably, have shortcomings stemming from imperfect data collection, data processing, and analytic methodology.

\subsection{Details about local implementation of community-based in-field address canvassing strategy in california}

On-the-ground implementation of the communitybased address canvassing strategy varied from county to county although project managers in each of the counties were aware of our initial targeting algorithm as a resource to provide guidance in identifying areas that would be likely to have unconventional and/or hidden housing units not in the pre-LUCA MAF.

Based on experience in the pilots of the communitybased address canvassing, our advice to the local initiatives where we were actively involved in discussing strategy (in Counties B,D,E, and F) was to use the "bad MAF" algorithm to, first, identify census block groups or tracts not to canvass and, then, to consult with local grassroots organizations working in lowincome neighborhoods to identify high-priority areas for canvassing among the census tracts the algorithm predicted to have a significant proportion of unconventional or hidden housing units likely not to have been included in the MAF.

Core PDB variables (drawn from the ACS 20122016 dataset) used in constructing the initial "bad MAF" targeting algorithm included: $\%$ of households in poverty, $\%$ of crowded households, $\%$ of noncitizens, \% with less than a high school education, $\%$ of households without health insurance, $\%$ of household not speaking English well. Because the targeting algorithm includes the ACS-derived variable of \% non-citizens, which is reported only at the census tract level of geography, our basic targeting algorithm could only be used at the census tract level, although in some counties, planners decided to review targeted census tracts and canvass only a sub-area of the tract. 
Analysis of the "yield" from the community-based in-field address canvassing - the \% of previously omitted unconventional and/or hidden housing units added to the MAF shows, as is reported in Table 1, that the targeting approach worked well enough to yield a significant return on investment in the areas which were targeted: from $0.6 \%$ to $7.1 \%$ improvements in MAF completeness.

\subsection{Lessons learned from targeting in-field address canvassing In LUCA}

Although the "bad MAF" targeting algorithm was useful in identifying census tracts and block groups where the MAF had some low-visibility housing units the exact yield of newly-identified housing units as percent of newly-identified low-visibility housing units added to the MAF from canvassing a particular census tract was not very reliably predicted, ranging from $0 \%$ to $53.5 \%$. With limited resources available for in-field address canvassing, targeting is essential, but it must be supplemented with local insights and its limitations must be understood.

Further efforts to refine a targeting algorithm to identify areas in urban communities where unconventional and/or hidden housing units are relatively prevalent would be well-justified - particularly since the Census Bureau's now plans to conduct in-field canvassing in 2019 in areas with about $30 \%$ of the housing units in the U.S. Refining the algorithm for targeting in-field canvassing should not be treated as simply a statistical exercise but, rather, as a multi-disciplinary endeavor to improve operational procedures for generating census (or other survey) data in the United States and internationally.

In the context of central government census-taking and other federal, state, or local government surveys that rely on housing data as a sampling frame, it would be wise to take into account sociological factors which lead to development and occupancy of unconventional and hidden housing and give greater attention to the ways in which data collection methodology and tabulation may compromise the data incorporated into such models. Migration network dynamics, for example, provide some of the explanation for housing conditions and patterns - in the United States and most other countries.

\subsection{The need to better understand the shortcomings of MAF-building procedures}

The implicit theory underlying the U.S. Census Bu- reau's Census 2020 Operational Plan to prioritize remote rural areas such as northern Maine, Alaska and disaster areas for in-field address canvassing in 2019 while devoting few resources to canvassing in urban areas with city-style addresses, is flawed.

It reflects inadequate analysis of the ways in which housing units come to be included (or not) in its Master Address file and how these processes function in different areas of the nation. For example, in some disaster areas, the Census 2020 Master Address File may be quite easily repopulated with information from administrative records on newly-constructed housing units (e.g. housing units built to replace those lost by fire in 2017 in a terrible fire season for California).

In some local jurisdictions, such as New York City, where there have been energetic efforts for more than a decade to improve administrative records on housing as part of a strategy to improve the city's census enumeration, administrative records are quite good [16]. In other jurisdictions without the financial resources, or organizational sophistication to improve their record systems, they may be useless. There is to date, no mapping of the adequacy of local records on housing and New York City is likely to be the exception rather than the rule.

At the same time, the Census Bureau's rationale for deploying its limited resources for in-field address canvassing to remote rural areas, fails to take into account the reality that the U.S. Postal Sequence Delivery File does not include many of the hidden housing units in urban areas. Many of the most marginal households living in low-visibility housing accommodations rely on P.O. boxes for mail and families living in hidden housing units share the mailbox with the "main house" on the property; consequently, the places they live are not identifiable as separate housing units.

Commercial mailing lists have shortcomings similar to the U.S. Postal Sequence Delivery File - since the economically marginal households living in these types of housing do not often order goods by mail and, if they do, are often forced to use a place with an existing postal address to have goods sent to which is not their residence. It appears that some, but not all, emergency response (E911) systems incorporate local observations of hidden housing units. However, the usefulness of utility records, telephone records, and cable service as a basis for identifying hidden housing units is questionable since all are linked to an official postal address.

To put the situation in context, it is worthwhile to note that developed countries such as the United States 
must confront the reality that the adequacy and reliability of many types of administrative records are questionable in a societal context where socioeconomic inequality persists. Households which are economically marginal, or sociologically marginal, or both (as is the case for many undocumented immigrants to the U.S.) are underrepresented in most administrative records. [17]

\section{Limitations to predicting the prevalence of unconventional and/or hidden housing omitted from the MAF}

The U.S. Census Bureau invested some effort and resources into developing a targeting algorithm with resolution down to the census block level in order to guide in-field canvassing efficacy [18]. However, it determined that even the sophisticated statistical models it had developed were not adequate to guide in-field address canvassing for Census 2020.

Nonetheless, in order to determine what could be learned from the California community-based canvassing initiatives, we reviewed the results of the community-based address canvassing efforts in the six counties studied to see what could be learned in order to further refine the "bad MAF" targeting algorithm that had been used in the LUCA-linked in-field address canvassing. In the course of this analysis we identified some inherent limitations to a PDB-derived targeting algorithm which we discuss below.

\subsection{Renter vs. homeowner: Practical limitations on building an algorithm to identify yield of newly-added unconventional housing units}

The U.S. Census Bureau's coverage measurement of housing units in 2000 and 2010 found that housing units occupied by renters were slightly more likely to have been omitted than those occupied by owners [19].

We had been inclined to consider \% renters in a lowincome tract as an indicator there might also be unconventional and/or hidden housing units. But this was infeasible, in part because in the counties which conducted in-field address canvassing, most tracts have a high proportion of renters and there's not much variation. However, the proportion of renter-occupied housing units in a tract was not explanatory in predicting prevalence of unconventional and/or hidden housing.

The traditional sociological distinctions, the "meaning" of differences between homeowners and renters, is less clear-cut in the communities where the community-based canvassing took place. In many of these urban neighborhoods where immigrants have settled, older lower-income blue-collar workers became homeowners when homeownership was cheaper than it is currently while younger, more affluent families can only rent at this point in time.

Canvassers' observations in the LUCA pilots and in the broader roll-out of the community-based in-field canvassing effort were that unconventional and/or hidden housing accommodations arise in some neighborhoods not only because some families are economically hard-pressed due to extremely high cost of renting but also because some of the low-income homeowners need additional income. The California Budget and Policy Center analysis show, for example, that $16.8 \%$ of California homeowners with mortgages, as well as $28.8 \%$ of renters spent more than half of their monthly income on shelter [13]. Unconventional housing is usually created by a homeowner who converts a garage into living quarters, builds a shed in a backyard, or adds on to the "main house" an additional small unit to rent out. Some of the canvassed neighborhoods with the highest proportions of unconventional housing units were ones where, PDB data showed that owneroccupied housing units predominated.

Whether or not this sort of non-formal housing construction is included in municipalities' or counties' records is likely to vary from county to county based on building code/planning department enforcement resources and policy and from neighborhood to neighborhood within cities and counties.

Consequently, previous analyses of differences between renter-occupied and homeowner-occupied housing are probably not a useful indicator for determining where housing units being left out of the MAF in the context of California urban areas where shelter costs are extraordinarily high.

\subsection{Inherent limitations of a PDB-based algorithm to predict yield of newly-added unconventional housing units}

It is also worthwhile to note that the margins of error for the PDB variables which might potentially be useful for targeted in-field address canvassing (typically percentage of households with a given predictor characteristic believed to be correlated with prevalence of low-visibility housing in a tract) are very large. For example, the PDB variable "undeliverable as addressed" (UAA) intrigued us as a possible indicator of problem- 
atic MAF quality, but the values for this variable are low and, consequently the margin of error is so large in relation to the standard deviation in values of the variable as to make it futile to reliably examine variations.

Other intriguing predictor variables such as percent of newly-constructed housing in a tract have, due to recent trends in housing development such as remodeling/rehabilitation in lieu of new construction, become more difficult to interpret. Similarly, Census 2010 coverage measurement showed that renter-occupied trailers were disproportionately omitted from the MAF ( $5.8 \%$ omission rate). From the on-the-ground perspective this is definitely the case in some areas but not in others. This appears to be a result of different counties' regulations regarding placement of mobile homes and commitment to enforcing regulations.

In piloting the strategy of community-based address canvassing, an earlier version of the "bad MAF" algorithm based on block-group level PDB data was used. But, of course, for these smaller geographies, the margin of error was larger relative to the values of component variables in the algorithm than at the census tract level and the variable of percent non-citizens was not available.

Our conclusion is that the inevitably imperfect match between areas defined by census geography and actual neighborhood housing patterns will make it difficult to further refine a PDB-based algorithm for targeting in-field address canvassing designed to definitively identify areas where hidden housing units are more prevalent.

This does not mean that targeting is not useful; it simply means that it is imperfect and that that there is a sound rationale for supplementing quantitative analysis for predicting where MAF quality is impaired due to omissions of hidden housing with qualitative insights based on observations by knowledgeable local community organizations.

\subsection{An unexpected but useful correlate of prevalence of hidden housing units: Educational attainment}

Despite the limitations of PDB data for constructing a "bad MAF" targeting algorithm, one of the ACSderived variables in the PDB that does show promise as a "non-structural" indicator of the prevalence of hidden housing is educational attainment. Its utility as a predictor of yield of newly-identified hidden housing units probably stems from its correlation with economic marginality in the $21^{\text {st }}$ century labor market and, consequently living in marginal, unconventional housing.
In City A and in County $\mathrm{C}$, the percent of households without a high school education in a tract was significantly correlated with yield of newly-identified hidden housing units from community-based canvassing. In City A, the PDB variable "non-HS graduate" explained almost $25 \%$ of variance in tract-level yield of newly-observed unconventional housing $\left(R^{2}=0.249\right.$, $p<0.000)$; in County C, $17 \%\left(R^{2}=0.173, p<\right.$ $0.001)$.

The current PDB variable of educational attainment is a constructed one and not quite ideal because it does not include continuous values for ACS respondents actual educational attainment. All that is available in the PDB are pre-determined categorical values so, at the lower end of the values for this PDB variable, all that is available for determining the prevalence of lesseducated heads of household and family members is "not HS graduate". However, for Mexican and Central American immigrants, a major sub-population in these areas, there is a divide in labor market possibilities between those with no education or only an elementarylevel education and those who completed, for example, 9-10 years of schooling and have basic literacy skills.

We realized - too late to include in the effort to develop a practical "bad MAF" targeting algorithm - that the best variable would be one drawn directly from ACS tract-level tabulations where educational attainment is reported as a continuous variable. Subsequent efforts to improve targeting in-field canvassing would benefit from using the full ACS dataset where educational attainment variable is reported as a continuous variable. We expect the correlation between low educational attainment and economic marginality will be strongest where "low" educational attainment is defined as $<7$ years of schooling and coupled with very limited English. The correlation between educational attainment and earning power is, however, an imperfect one also because in some industry segments and communities, there are good labor market opportunities for less-educated workers.

Our data for analyzing the "yield" of hidden housing units was limited to the census block groups or tracts that were chosen for canvassing. Since these areas had already been identified as likely to have low-visibility housing, the variables in the "bad MAF" our analysis of the effectiveness of the targeting algorithm inevitably has limited impact since it only examines variations in "yield" of newly-identified unconventional and/or hidden housing units within these previouslytargeted areas. 


\section{Community-based canvassers' observations of complex households - implications for census accuracy}

The tabulations of newly-observed unconventional housing arrangements discussed here include only unconventional housing units as defined in the U.S. Office of Management/Census Bureau residence rules, not "complex households", also referred to as "doubled-up" households, or as "joint households" where multiple family units, social units, or individuals live in housing accommodations within a housing unit that has only a single outside entrance.

These housing units, referred to as complex households or "joint" households were not included in the tally of proposed MAF additions reported here because, according to the residence rules, they are not separate housing units. The decision not to tabulate these as additional housing units to be added to the MAF was made in consultation with the Census Bureau's LUCA Program Manager so as to assure that newly-identified housing units would be valid housing unit additions to the MAF.

Nonetheless, the complex households, "joint households" represent a serious housing-related structural cause of undercount. About $20 \%$ of all the unconventional housing arrangements observed by community canvassers in City A and County F consisted of "doubled-up" households (complex households).

It is likely that the actual prevalence of complex households may be even higher in some immigrant settlement areas. Prior research in farmworker communities in Woodburn, Oregon, Arvin, California, and other rural areas with dense settlements of mostlyundocumented immigrant farmworkers [20], showed that complex households/doubled-up crowded housing were very common among mature/dominant migration network but, also, among other underemployed and seasonally employed immigrants. Moreover, in some cases, although these ad hoc crowded housing arrangements might, in some respects, be considered group quarters (GQs) they did not fully conform to the core definition - since there was no facility manager.

A recent study of housing in California's Salinas Valley shows that in this area, where there has been a large influx of H-2A workers, crowded housing and complex households are the norm. Findings from the study's survey of farmworkers found that $54 \%$ lived in complex doubled-up households, that, on the average, there were 3.2 non-family members in the doubled-up households, and that housing was extremely crowded with, on the average, 2.3 persons per room [21].
Not much is known quantitatively about the extent to which the primary household's census respondent includes or omits peripheral people living in the same housing unit from their census response. There is, however, reason to believe that in low-income neighborhoods with dense settlements of immigrants, householders will be more reluctant to include peripheral individuals living in their housing unit on their household census roster - because, in many cases, the additional people living in the housing units are newcomers and undocumented. The Salinas Valley research shows that the partial household omissions when these peripheral members are left off householders' census tally of "persons living here" will be an important factor in undercount - since the non-family members make up $45 \%$ of the population living in these crowded, complex households.

Overall, the research on immigrant settlement, the Census Bureau's own ethnographic research in Census 1990 and more recently, as well as other non-census research on immigrant settlement patterns, indicate there will be substantial challenges in assuring enumeration of "complex households" in Census 2020 [22,23]. The ethnographic research shows that, particularly in immigrant communities, the tacit ambiguity regarding "household" and "housing unit" incorporated into the residence rules and its clash with census respondents' own thinking about the concept of "household" will be extremely problematic in urban areas as well as in the immigrant farmworker areas.

Despite census instructions seeking to assure that the householder responding to the census will include "everyone living here" in their tally of "household members", the inherent definitional contradiction is powerful. Few of the peripheral persons living in housing units which are referred to as "complex households", i.e. housing units with multiple households living in them, will be included on the "household roster" filled out by the primary census respondent. This particular cause of differential census undercount - which disproportionately affects enumeration of poor families doubling up in crowded housing to make ends meet - is an important cause of undercount. We also learned, in the course of research several decades back that many Hispanic households consider it improper to provide the Census Bureau with personal information about the other social units/households who share a housing unit with them [24]. It is to be expected that if Census 2020 includes a question on citizenship for each person listed on the household roster, the reluctance of immigrant heads of household of core family 
households to report "extra persons" living at the place they live will increase dramatically.

Under ideal circumstances, each social unit/family in these multi-family unit living quarters would receive its own census notification and be encouraged to submit its own census response but this is not part of the Census 2020 design. Community-based canvassing carried out in conjunction with Census 2020 may provide valuable insights for crafting local efforts to address this problem during subsequent phases of Census 2020 operations.

\section{Fiscal viability of community-based in-field address canvassing}

Although reliable detailed data on the overall cost of implementing the community-based address-canvassing strategy is not currently available, we do have data from our piloting community-based address canvassing in two counties where the in-field initiative was implemented entirely by a community organization team of grassroots canvassers. In those projects (where information on newly-identified housing units was submitted to the California state LUCA liaison), it is estimated that the total cost was probably about $\$ 40$ for each newly-identified hidden household added to the MAF.

Since federal program funding driven by census data (from the decennial census and the ACS) averages about $\$ 1,000$ per year for each additional Californian enumerated, local stakeholders' return on investment in achieving a complete census count is very high. Because the average household living in areas with unconventional and/or hidden housing has about 3.5 persons in it and because the decennial census count has an impact on allocation of federal funding throughout the entire post-censal decade - the return on investment in adding unconventional and/or hidden housing units to the address list for a local area in California is typically at least $\$ 35,000$ for each household that, as a result of being in the MAF, had a greatly-improved opportunity to be enumerated. Therefore, the return on investment in LUCA-linked community-based address canvassing should increase California's share of federal funding by about $\$ 455$ million over the decade from 2021-2030. It deserves note that the returns on investment per additionally enumerated individual in California are lower than in many other U.S. states due to the way census data enters into allocation of funding for several major federally-funded health care programs [25].
In non-financial terms the "return on investment" is that some of the most economically marginal families and individuals living in the worst housing accommodations in the U.S. have an opportunity to be included in the census-based profile of the American population.

\section{Implications and recommendations}

Time is short before Census 2020 takes place. But there is still time to reconsider whether partnerships between the U.S. Census Bureau, local government, and local community-based organizations, can be configured so as to implement a "rapid response" last-ditch push to improve the MAF before 2020.

The Census Bureau's budget constraints are real and serious but what is needed even more than additional funding to assure adequate in-field address canvassing in urban areas and rural areas with extensive immigrant settlement is the flexibility to develop collaborative effective partnerships to improve the MAF. Even if it turns out to be infeasible for the U.S. Census Bureau to implement targeted local MAF improvement efforts to add the unconventional and/or hidden housing units to the MAF in 2019, these considerations should be incorporated in census planning for 2030.

Insights drawn from in-field canvassing can also be used as a valuable resource for the Census Bureau's efforts to identify uninhabitable housing units to delete from the NRFU workload and to enhance quality assurance in NRFU - particularly in areas where Census Bureau enumerators' workload is very high. [26]

\subsection{Census Bureau 2019 in-field canvassing should include urban areas where unconventional and hidden housing is prevalent}

The Census Bureau's plans for prioritizing Census 2020 address canvassing primarily in remote rural areas will increase differential undercount rather than diminish it, except in Alaska and areas with concentrations of American Indian populations where the rural canvassing should continue to be a priority. Infield address canvassing focused on identifying lowvisibility housing in rural areas is important, but more important than remoteness or population density is socioeconomic context. The continuing omission of rural housing where migrant and seasonal farmworkers (MSFW's) and other low-income rural populations reside from the MAF stems from prevailing local practices vis-à-vis housing and economic marginality in the 
local labor market. In California, areas with concentrations of rural immigrant settlement, low-visibility housing units are prevalent in rural areas classified as urban fringe areas. [27]

Even with limited funding, it makes sense to allocate a reasonable portion of the Bureau's address canvassing budget to in-field canvassing in low-income urban neighborhoods with high proportions of minority and immigrant-headed households as well as to rural areas.

In California, for example, we hypothesize that infield canvassing of areas in areas with about $20 \%$ of the state's 14.1 million housing units would be required to assure that low-income minority households living in marginal housing conditions - in unconventional or hidden housing units - have an equitable opportunity to be enumerated. Since only one-third of the areas likely to have higher-than-average prevalence of unconventional and/or hidden housing were covered in the course of community-based in field address canvassing LUCA in 2018, a reasonable strategy would be for the U.S. Census Bureau to target the remaining $13 \%$ where LUCA only consisted of in-office canvassing using administrative records - an incomplete and uneven source of information on hidden housing.

\subsection{Census bureau collaboration with local community organizations has great promise}

"Pre-canvassing" discussions and review of census tracts tentatively targeted for in-field canvassing with knowledgeable local community groups and service providers can yield valuable insights to revise initial in-field address canvassing plans and refine targeting. In California's LUCA-linked community-based address canvassing, knowledgeable organizations and individuals had valuable first-hand insights about local housing accommodations (e.g. from home visits in the course of providing services to low-income households, from health outreach efforts, from staff living in the neighborhood). These insights made important contributions to the LUCA-linked targeted in-field canvassing. In current plans for U.S. Census Bureau infield address canvassing in 2019, and If future decennial census operational plans envision in-field address canvassing for only a sub-set of U.S. areas, incorporating that sort of consultation should be incorporated into the Census Bureau's targeting of its own efforts.

Census Bureau-grassroots organization partnerships can also provide crucial insights to enhance the effectiveness of urban in-field address canvassing if the Census Bureau's regional offices and local area census offices are allowed the flexibility to rely on culturallyastute local members of "hard to count" communities to develop in-field canvassing strategies that incorporate this sort of local contextual intelligence. These insights include knowledge about where to look for unconventional and hidden housing units and, also, how to identify such units.

Census Bureau-local partnerships to conduct in-field address canvassing provide a vivid acknowledgement of the value and power of social networks as a resource for civic initiative.

This positive experience in implementing the LUCA-linked community-based in-field address canvassing can also serve as a model for re-aligning perspectives on census partnership and to broaden and deepen partnerships to craft messaging about census. The U.S. Census Bureau's local partnerships have, in the past, too often been devoted toward amplifying centrally-developed messages, and too seldom, oriented toward brainstorming to identify novel and locally-powerful strategies to broaden census participation. The U.S. Census Bureau has officially made a commitment to "design thinking"; but this commitment is at odds with the institution's very centralized organizational culture and provides no obvious opportunities for "bottom-up" flow of innovation or optimal collaboration with local stakeholders. Similar realignment of perspective is particularly necessary in facing the challenges faced that confront less-developed countries.

New perspectives on Census Bureau-local partnerships can also provide an opportunity for local communities to assert their distinctive identity, underscore the importance of including "hard to count" families and individuals in the over-arching commitment to count everyone at the right place, and, thereby, offering a way to make the decennial census a better mirror of America. This, too, would be an expected outcome from international commitment to more decentralized approaches to survey research and census implementation.

\subsection{Priority should be given to hiring locally-knowledgeable culturally-competent individuals to conduct in-field address canvassing and enumeration}

In each community where the LUCA-linked community-based initiatives were implemented, canvassers relied on their knowledge of local areas to approach canvassing in ways that were probably more 
effective than standard address canvassing as implemented by the Census Bureau. For example, in County F community canvassers knew it would be useful, wherever possible, to walk along back alleys where the entrances to unconventional housing were more visible than at the front of properties. In City A, looking closely to see if garage doors had weatherproofing was a helpful clue. In a farmworker community with extensive ad hoc housing add-ons behind fences, it was useful for canvassers to look carefully to see if housing units with a single address had multiple swamp coolers along the roofline. These sorts of context-sensitive insights can be incorporated into local training for address listers.

The local organizations that were mobilized to collaborate with city and county LUCA partners during the spring of 2018, and ones like them in other areas of California and other states, are a particularly valuable resource for recruiting and orienting culturally competent local individuals to serve as address listers for the U.S. Census Bureau's in-field address canvassing in 2019. These organizations' collaboration in framing the role of address listers as contributors to social and economic equity in their local communities will significantly help the Census Bureau in the formidable challenges it faces in recruiting field staff who can carry out the difficult tasks assigned them.

Local insights derived from community-based canvassing can also eventually contribute to the efficacy of NRFU and quality of imputation in neighborhoods with low self-response - particularly in neighborhoods where doubled-up housing arrangements are common. While most efforts to promote census participation focus on activities meant to generally improve selfresponse, customized local campaigns might specifically stress the desirability and safety of householders' including information on non-family members who live in crowded households with them.

To enhance its address canvassing results and enhance the effectiveness of non-response followup by enumerators, the U.S. Census Bureau should adapt its recruitment and screening procedures to assure hiring an adequate number of locally-knowledgeable canvassers with established relationships and welldeveloped communication skills in hard-to-count neighborhoods.

\section{Conclusions}

Community-based address canvassing provides a way to achieve an important commonly agreed-upon societal objective - assuring a fair and accurate census count. It works by deploying local cultural capital (local knowledge, language and persuasive communication skills) and social capital (community-based networks working to conduct canvassing campaigns) in order to complement shortage of financial capital, i.e. the Census Bureau's budget shortfalls which resulted in the decision to truncate in-field address canvassing to only $30 \%$ of US addresses and in local communities which have a limited municipal or county budget.

It is perhaps inevitable, in an era when a broad spectrum of U.S. policy advocates is questioning the primacy of the federal government in many areas and reluctance to adequately fund central government statistical endeavors is growing, that more attention will need to be given to designing innovative and costeffective civic partnerships between non-governmental organizations, local and state government, and the U.S. Census Bureau to work toward a fairer and more accurate enumeration of an increasingly diverse population.

This broad policy issue of central government, local government, and non-governmental organization partnerships deserves attention internationally, where it has sometimes been assumed that central government needs to play the dominant role or take unilateral responsibility in implementing statistical initiatives. Resource-rich developed countries designing program interventions in less-developed countries have been prone toward technical assistance for institutional capacity-building which replicates their own more-adequately funded institutions and organizational schema without adequate consideration of ways to tailor program investments to resources available in-country. In particular, development policy oriented toward building less-developed countries' statistical programs would benefit from more attention to ways to integrate local resources of social, cultural, and civic capital into collaborative data collection and research.

From this perspective, the U.S. Census Bureau's cost-driven decision to drastically reduce its in-field address canvassing from $100 \%$ of U.S. housing to $30 \%$ has been a useful "natural experiment" in that it has generated additional thinking about ways in which LUCA, the local update of census addresses, instituted originally in response to pressure from local government, could be made more effective if it were to include in-field address canvassing, not just in-office canvassing relying on local administrative records. The questionable federal decision to truncate in-field address canvassing and California's response highlight 
the viability of local communities taking on greater responsibility for in-field address canvassing in order to improve the MAF and, ultimately, census enumeration in their local communities.

A remaining barrier to moving forward with further MAF improvement is that the importance of a complete and accurate Master Address File for decennial census (and American Community Survey) data quality is not widely-understood - by the public, local officials, and other stakeholders generally committed to collaboration to assure "a complete census count". The multiple ways in which differential undercount compromises census accuracy and practical utility of demographic and socioeconomic data are not yet fully understood.

Nor is it generally understood that unconventional housing makes up a disproportionate share of housing units left out of the MAF. The initiative which integrated community-based address canvassing into California's 2018 LUCA effort shows that it is possible, though not easy, to develop such awareness and forge effective partnerships to augment the Census Bureau's constrained ability to fully cover the entire U.S. with in-field address canvassing.

The outcome of the LUCA 2018 efforts to rollout community-based in-field address canvassing in several California counties shows that it was possible to rapidly configure partnerships to implement the strategy within a very constrained time frame once a decision had been made to adopt this strategy. Non-government organizations, foundations, a national non-profit (Cities of Service), proactive city government officials, and local, technically sophisticated non-profits, and grassroots organizations all contributed to piloting the strategy of community-based address canvassing in December 2017 and January 2018. Results from this pilot provided useful proof-ofconcept for rolling out the strategy more broadly in the very short window of LUCA - from March-July, 2018.

Moving forward to build on lessons learned in this effective collaboration will require new visualization about the nature and scope of Census Bureau partnerships with local stakeholders. In particular, there will be the need for more attention from all partners to the real-world micro-environment in neighborhoods, census tracts, communities which are now visualized simply as being "hard to count" using the LRS (lowresponse score) indicator. This is because this indicator is linked to only a single facet of census operations self-response and the resulting NRFU workload.

The basic proposition that LUCA participation would be voluntary and supported by local govern- ments that recognized the high stakes for their own financial well-being is understandable. Nonetheless, It is not an adequate approach for improving census fairness even if it contributes to generally-improved census accuracy. This is because efficacy of LUCA participation is so uneven. Many municipalities and counties where the MAF is flawed due to omission of unconventional housing lack the organizational capacity and/or financial resources to undertake in-field canvassing and have limited technical capability to conduct in-office canvassing.

The challenges faced in implementing collaborative statistical surveys based on central and local government partnership is still more problematic in the international context. In many countries, for example, local government has extremely limited taxing authority and local government financial resources are minimal. In those countries, as in some regions of the United States, local government may not be well-positioned fiscally to take the initiative in collaboration for census improvement. Central government strategy needs, ideally, to provide funding for their local government partners to fully realize the potential of these collaborations or, at the very least provide, deeper and redesigned sorts of technical assistance than was available for LUCA partners in 2018. Part of California's energetic efforts in the LUCA process stemmed from state government having the vision to allocate modest amounts of funding (\$7 million) statewide to support LUCA implementation by local partners.

Yet, despite this proactive step forward, a serious constraint was the low level of awareness among local government entities about the limitations of "in-office" address canvassing (using administrative records and satellite imagery) and the promise of low-cost "in field" local address canvassing conducted by community organization that had previously not been part of LUCA partnerships.

California's experience in LUCA 2018 shows that community-based address canvassing as a tool for improving the MAF is cost-effective. The Census Bureau can and should find ways to incorporate into its own implementation of LUCA and its own infield canvassing in the future. Reconceptualizing the nature and extent of federal-local government collaboration in LUCA to include activists from undercounted communities as additional valuable partners should be the fulcrum for moving to implement the concept of "continuous MAF improvement so lucidly and astutely championed some years back by a planner who has made MAF improvement a priority in 
New York City's efforts to secure an accurate census count $[16,26]$. A commitment to continuous MAF improvement and innovative collaboration with local stakeholders is clearly a win-win proposition.

\section{References}

[1] Swartz R, Virgile P, Timko B. 2010 Census Local Update of Census Addresses Assessment: Final Report, Geography Division, U.S. Census Bureau. 2012 Available from: https:// daks2k3a4ib2z.cloudfront.net/59fb4f76691c1b000103c309/ 5a0b8247bb994d000128ad31_LUCA\%20Swartz\%202010_ Census_LUCA_Assessment.pdf.

[2] U.S. Census Bureau, 2020 Census Operational Plan: A New Design for the 21st Century (v. 3), September, 2017. Available from https://www.census.gov/programs-surveys/decennialcensus/2020-census/planning-management/planning-docs/ operational-plan.html.

[3] Kissam, E., An Effective Strategy To Reduce Census Undercount: Results from California Pilots of CommunityBased Address Canvassing, March, 2018. Available from: http://www.wkfamilyfund.org/docs/March-24-CB-AdCan\% 20Updated.pdf.

[4] Government Accountability Office 2020 Census: Actions Needed to Address Challenges to Enumerating Hard-to-Count Groups, 2018. Available from https://www.gao.gov/products/ GAO-18-599.

[5] Fein DJ. The social sources of census omission: Racial and ethnic differences in omission rates in recent censuses, Ph.D. dissertation, Princeton University, 1989.

[6] Fein DJ, West K. The Sources of Census Undercount: Findings from the 1986 Los Angeles Test Census, Survey Methodology, 1988 Dec.

[7] De La Puente M. Using Ethnography to Explain Why People are Missed or Erroneously Included by the Census: The Evidence from Small Area Ethnographic Studies, Center for Survey Methods Research, U.S. Census Bureau https://www. census.gov/srd/papers/pdf/mdp9501.pdf.

[8] Dominguez B, Mahler S. Alternative Enumeration of Undocumented Mexicans in South Bronx. U.S. Bureau of the Census, Washington, D.C. 1993.

[9] Hamid A, Brownrigg L. Accurate Address Listings to Improve Housing and Population Counts: A Comparison of Address Listings and Enumerations of Four Sample Areas by the 1990 Decennial Census, the Post- Enumeration Survey (PES) and the Alternative Enumeration (AE). 1992. Available from https://www.census.gov/srd/papers/pdf/lab9301.pdf.

[10] Government Accountability Office, Lessons Learned for Locating and Counting Migrant and Seasonal Farmworkers. 2003 Available from https://www.gao.gov/products/GAO-03605.

[11] Sherman J, Villarejo D, Garcia A, McCurdy S, et al. Finding Invisible Farmworkers: The Parlier Survey. California Institute of Rural Studies, 1997.

[12] Kissam E, Jacobs I. Practical research strategies for Mexican indigenous communities in California seeking to assert their own identity. In J. Fox \& G. Rivera-Salgado (Eds.), Indigenous Mexican Migrants in the United States. San Diego, CA: Center for U.S. Mexican Studies, University of California, 2004.
[13] Kimberlin S, Poverty and Housing Costs in California, California Budget and Policy Center, 2017.

[14] U.S. Census Bureau Planning Database Documentation available from https://www.census.gov/research/data/planning database/2018/docs/2018_Tract_PDB_Documentation_V4. pdf.

[15] Kissam E. Differential undercount of Mexican immigrant families in the U.S. Statistical Journal of the IAOS 33 (2017), 797-816.

[16] Chiusano M, Joseph Salvo is Responsible for Making Sure Each New Yorker Counts, AM Network, March 5, 2018. https://www.amny.com/opinion/columnists/mark-chiusano/ joseph-salvo-is-responsible-for-making-sure-the-censuscounts-every-new-yorker-1.17130776.

[17] Bhaskar R, Fernandez L, Porter S. Assimilation and coverage of the foreign-born population in administrative records, Statistical Journal of the IAOS 34 (2018), 191-201.

[18] Heim K, Raim A. "Predicting Coverage Error on the Master Address File using Spatial Modeling Methods at the Block Level”, Proceedings of the American Statistical Assn., 2016.

[19] Mule T, Konicki S. "2010 Census Coverage Measurement Estimation Report: Summary of Estimates of Coverage for Housing Units in the United States", Census Bureau, May, 2012.

[20] Kissam E. "Migration networks and processes of community transformation: Arvin, California and Woodburn, Oregon", Journal of Latino and Latin American Studies, 2007.

[21] California Institute of Rural Studies, "Farmworker Housing Study and Action Plan for the Salinas Valley and Pajaro Valley April, 2018. Available from https://donvillarejo.github. io/Fulltext/Farmworker-Housing-Study-and-Action-Plan-forSalinas-Valley-and-Pajaro-Valley_2018-Jume.pdf.

[22] Schwede L Complex Households and Relationships in the Decennial Census and in Ethnographic Studies of Six Race/Ethnic Groups: Final Report, Statistical Research Division, U.S. Census Bureau 2003 Aug. Available from https:// www.census.gov/pred/www/rpts/Complex\%20Households $\%$ 20Final\%20 Report.pdf.

[23] O'Hare WP, Mayol-Garcia Y, Wildsmith E, Torres A. The Invisible Ones: How Latino Children are Left Out of our Nation's Census. Child Trends: Hispanic Institute, 2016. Available from ftp://ftp.census.gov/cac/nac/meetings/2016.

[24] Kissam E, Herrera E, Nakamoto J. Hispanics' Response to Census Forms and Procedures. Aguirre International, Final Report to Population Division, U.S. Census Bureau, 1993.

[25] Reamer A. Counting For Dollars: The Role of the Decennial Census in the Geographic Distribution of Federal FundsReport \#2 Fiscal Costs of an Undercount to States. 2018, March https://gwipp.gwu.edu/sites/g/files/zaxdzs2181/f/ downloads/GWIPP\%20Reamer\%20Fiscal\%20Impacts\%20of $\% 20$ Census $\% 20$ Undercount $\% 20$ on\%20FMAPbased\%20Programs\% 2003-19-18.pdf.

[26] Salvo J, Arun PL, Misclassifying New York's Hidden Units as Vacant in 2010: Lessons Gleaned for the 2020 Census, Population Research Policy Review, 2013.

[27] Strohlic R, Courville M, Toward A. New Definition of Rurality in $21^{\text {st }}$ Century California, California Rural Legal Assistance, 2011. Available from http://www.crla.org/downloadcenter-rural-justice-forum. 